\title{
INFLUENCE OF GUANIDINE DERIVATIVES ON THE SPECIFICITY OF MALT CARBOXYPEPTIDASE
}

by

\author{
KLAUS BREDDAM and MARTIN OTTESEN
}

Department of Chemistry, Carlsberg Laboratory, Gamle Carlsberg Vej 10, DK-2500 Copenhagen, Valby

Keywords: Specificity, deamidation, phenylguanidine, carboxypeptidase, barley, malt

Malt carboxypeptidase (Carlsberg Res. Commun. 48, 217-230, 1983) catalyzes hydrolysis of ester substrates with the general formula $\mathrm{Bz}-\mathrm{X}$-OMe with preference for substrates where $\mathrm{X}=\mathrm{Phe}$, Arg or Lys over those where the $\mathrm{X}$-position is occupied by an amino acid residue with a neutral or acid aliphatic side chain. The rapid hydrolysis of $\mathrm{Bz}$-Phe-OMe is mainly due to a high $\mathrm{k}_{\mathrm{cat}}$ value while for $\mathrm{Bz}$-Arg-OMe it is mainly due to a low $\mathrm{K}_{\mathrm{m}}$ value. Addition of salts result in decreased rates of hydrolysis of substrates where $\mathrm{X}=\mathrm{Lys}$ or $\mathrm{Arg}$ (positively charged) and increased rates of hydrolysis of substrates where $\mathrm{X}=\mathrm{Phe}$ or Leu (hydrophobic).

Guanido compounds influence the enzymatic properties of malt carboxypeptidase. Kinetic data for the hydrolysis of various substrates indicate that phenylguanidine binds to the $S_{1}{ }_{i}$ binding site of the enzyme in such a manner that the rate of cleavage of ester or amide substrates with large groups in the $\mathrm{P}_{i}$ position, i.e. -OEt, -OPr, -OBu, -Ala-OH, -Gly- $\mathrm{NH}_{2}$, is reduced while substrates with small groups in this position i.e. $-\mathrm{OMe},-\mathrm{NH}_{2}$ are hydrolyzed with increased rates. These observations have applications in deamidation reactions since the presence of phenylguanidine in the reaction medium results in a significantly increased yield of the deamidated product.

Abbreviations: $\mathrm{Ac}=$ acetyl; $\mathrm{BiGu}=2$-guanidobenzimidazol; $\mathrm{Bu}=$ butyl; $\mathrm{Bz}=$ benzoyl; $\mathrm{DFP}=$ diisopropylphosphorofluoridate; EDTA = ethylene diamine tetraacetic acid sodium salt; $\mathrm{FA}=$ furylacryloyl; $\mathrm{Gu}=$ guanidine hydrochloride; Hepes $=\mathrm{N}$-2-hydroxyethylpiperazine-N'-2-ethane sulfonic acid; HPLC $=$ high performance liquid chromatography; $\mathrm{MeGu}=$ methyl guanidine hydrochloride; $\mathrm{Mes}=2$-( $\mathrm{N}$-morpholino)ethane sulfonic acid; $\mathrm{PhGu}=$ phenylguanidine hydrogencarbonate; $\mathrm{PpGu}=1-(3$-phenylpropylamino $)$ guanidine hydrochloride; $\mathrm{Pr}=$ propyl; TEAP = triethyl ammonium phosphate; Tris = tris(hydroxy methyl) aminomethane; $Z$ = carbobenzoxy. Abbreviations of amino acids, amino acid derivatives and peptides are according to the guidelines of the IUPAC-IUB Commision on Biochemical Nomenclature. The binding notation for the enzyme and the substrates is that of SCHECHTER and BERGER. Accordingly, amino acid residues in the substrate are referred to as $P_{1}, P_{2} \ldots P_{i}$ in the aminoterminal direction away from the scissible bond and $P_{i}$ for the carboxy-terminal residue that is hydrolyzed off. Enzyme subsites are denoted $S_{1}, S_{2} \ldots . . . S_{i}$ and $S_{1}^{\prime}$ in correspondence with the substrate. 


\section{INTRODUCTION}

In a recent paper from this laboratory the isolation of a "serine carboxypeptidase" (E.C. 3.4.16) from malted barley was described (5) and it was demonstrated that this enzyme exhibited activities similar to carboxypeptidase $Y$ from baker's yeast, the most extensively characterized enzyme in this class $(9,13)$. However, the carboxypeptidases from malt and yeast differ substantially with respect to molecular weight and other physical-chemical characteristics.

The binding sites of proteolytic enzymes determine their specificity and chemical modifications of amino acid residues in these sites have provided information about enzyme-substrate interactions for such enzymes as subtilisin (20), thermolysin (1) and carboxypeptidase Y (4). In the latter case with interesting applications as a consequence $(5,6)$. The work by INAGAMI and MURACHI demonstrated that information about binding sites could be obtained by addition of various effectors (11). Hence, it was of interest to determine the side group specificity of malt carboxypeptidase and to investigate whether effectors would influence its enzymatic properties. In the present paper, it is demonstrated that malt carboxypeptidase exhibits a side group specificity with respect to the $P_{1}$ position of the substrate which is reminiscent of the specificity of subtilisin, and that phenylguanidine drastically change the enzymatic properties of the enzyme.

\section{MATERIALS AND METHODS}

\subsection{Materials}

Malt carboxypeptidase was isolated by affinity chromatography as previously described (5). All synthesized substrates were checked by HPLC as described in reference 22 , and it was ascertained that the purity was higher than $98 \%$. Bz-Arg-OPr and $\mathrm{Bz}-\mathrm{Arg}-\mathrm{OBu}$ were prepared by esterification of $\mathrm{Bz}-\mathrm{Arg}-\mathrm{OH}$ with propanol/HCl and butanol/ $\mathrm{HCl}$, respectively. The reactions went to completion as judged by HPLC analysis. After evaporation of the alcohol, the oil containing the esters was washed extensively with ether to remove residual alcohol, resulting in a white solid. Melting points: $143-144^{\circ} \mathrm{C}$ (Bz-Arg-OPr), $138-140^{\circ} \mathrm{C}$ (Bz$\mathrm{Arg}-\mathrm{OBu})$. Bz-Phe-OEt was synthesized from Bz-Phe-OH with ethanol/HCl and crystallized from ethanol/water. Melting point: $102-103{ }^{\circ} \mathrm{C}$. $\mathrm{Bz}-\mathrm{Pro}-\mathrm{OMe}$ was synthesized from Bz-Pro-OH with methanol/ $\mathrm{HCl}$ and recrystallized from ethanol/water. Melting point: $88-89.5^{\circ} \mathrm{C}$. Bz-PheHis- $\mathrm{NH}_{2}$ was made by enzymatic synthesis in the following way: $1.4 \mathrm{~g}$ histidine amide $\cdot 2 \mathrm{HCl}$ was dissolved in $25 \mathrm{ml} 1 \mathrm{~mm}$-EDTA and $\mathrm{pH}$ was adjusted to 9.5 by addition of $\mathrm{NaOH} .5 \mathrm{mg}$ carboxypeptidase $\mathrm{Y}$ was added followed by dropwise addition of $600 \mathrm{mg} \mathrm{Bz-Phe-OEt} \mathrm{dissolved} \mathrm{in}$ $3 \mathrm{ml}$ methanol. A precipitate was formed and after 25 minutes the reaction was quenched by addition of $200 \mathrm{ml} \mathrm{CH}_{3} \mathrm{CN}$. HPLC identification indicated that the reaction mixture consisted of $65 \%$ Bz-Phe-His- $\mathrm{NH}_{2}, 10 \% \mathrm{Bz}-\mathrm{Phe}-\mathrm{OH}$ and $25 \%$ $\mathrm{Bz}-\mathrm{Phe}-\mathrm{OEt}$. The reaction mixture was evaporated to dryness. Bz-Phe-His- $\mathrm{NH}_{2}$ was dissolved in water by addition of $\mathrm{HCl}$ until $\mathrm{pH} 2.6$ and subsequent recrystallization from ethanol/water yielded the pure product. Melting point: 189-192 ${ }^{\circ} \mathrm{C}$. The following compounds were synthesized as previously described: Bz-Gly-OMe (3), BzPhe-OMe (3), Bz-Ile-OMe (4), FA-Phe- $\mathrm{NH}_{2}$ (5) and FA-Phe-Gly- $\mathrm{NH}_{2}$ (5). FA-Phe-Ala-OH was a gift from Dr. S.B. SøRENSEN.

Bz-Ile-OH, Bz-Pro-OH, Bz-Val-OMe, Bz-His$\mathrm{OMe} \cdot \mathrm{HCl}$ and $\mathrm{Bz}-\mathrm{Met}-\mathrm{OMe}$ were from VegaFox Chemicals, USA. Methyl guanidine hydrochloride, Hepes, Trisma base, Mes, Bz-Arg-OMe and Bz-Arg-OEt were obtained from Sigma, USA. Phenylguanidine hydrogencarbonate, 1-(3phenylpropylamino) guanidine hydrochloride and 2-guanidino benzimidazol were obtained from EGA Chemie, W. Germany. All other peptides were purchased from Bachem, Switzerland. Other reagents and solvents were of analytical purity and obtained from Merck, W. Germany.

\subsection{Methods}

Esterase activity towards N-benzoylated amino acid esters was determined spectrophotometrically at $254 \mathrm{~nm}$ using a Cary 219 spectrophotometer thermostated at $25^{\circ} \mathrm{C}$. The specificity study was performed at $\mathrm{pH} 7.5$ (the $\mathrm{pH}$ optimum for malt carboxypeptidase catalyzed ester hydrolysis) using $0.3 \mathrm{~mm}$-substrate, $0.05 \mathrm{M}$-Hepes, $1 \mathrm{~mm}$-EDTA. The hydrolysis was followed to completion and $k_{\mathrm{ca}} / \mathrm{K}_{\mathrm{m}}$ values were determined from the integrated form of the 
Michaelis-Menten equation as described in reference 19. $\mathrm{k}_{\mathrm{cat}}$ and $\mathrm{K}_{\mathrm{m}}$ values for the malt carboxypeptidase catalyzed hydrolysis of Bz-Arg-OMe, $\mathrm{Bz}$-Arg-OEt, Bz-Arg-OPr and $\mathrm{Bz}-\mathrm{Arg}-\mathrm{OBu}$ in 0.05 м-Hepes, 1 mм-EDTA, pH 7.5 were graphically determined from Lineweaver-Burk plots, using substrate concentrations from 0.02 to 1.5 mM.

Esterase, amidase, peptidyl amino acid amide hydrolase and peptidase activities towards FAPhe $=\mathrm{OMe}$, FA-Phe $\rfloor \mathrm{NH}_{2}$, FA-Phe $-\mathrm{Gly}-\mathrm{NH}_{2}$ and FA-Phe $=$ Ala-OH, respectively, were measured spectrophotometrically at $337 \mathrm{~nm}$ and $25^{\circ} \mathrm{C}$. Esterase activity towards Ac-Arg-OMe was determined by the pH-stat method in $0.1 \mathrm{M}-\mathrm{KCl}, 1$ mM-EDTA, pH 7.5 (12).

Apparent dissociation constants $\left(\mathrm{K}_{\mathrm{d}(\mathrm{app})}\right)$ for the binding of $\mathrm{BiGu}, \mathrm{PpGu}, \mathrm{PhGu}$ and MeGu to the enzyme were determined according to the following equation (based on the assumption that the compounds at saturation bind to the enzyme in a ratio of 1:1):

$$
\mathrm{K}_{\mathrm{d}(\mathrm{app})}=\frac{[\mathrm{X}][\mathrm{E}]}{[\mathrm{XE}]}=\frac{[\mathrm{X}]\left(\mathrm{V}_{\mathrm{sa1}}-\mathrm{v}\right)}{\mathrm{v}-\mathrm{v}_{\mathrm{o}}}
$$

where $[X],[X E]$ and $[E]$ are the concentrations of free effector, effector bound to enzyme and free enzyme, respectively; $\mathrm{V}_{\text {sat }}$ and $\mathrm{v}$ represent rates at saturating and given concentrations of effector. $v_{0}$ represents the rate in the absence of effector. [X] was assumed to be equal to the concentration of added $X$. This holds since $\mathrm{K}_{\mathrm{d}(\mathrm{app})}$ is much larger than the total concentration of enzyme. The equation was used in its logarithmic form:

$$
\log [X]-\log \mathrm{K}_{\mathrm{d}(\mathrm{app})}=\log \frac{\mathrm{v}-\mathrm{v}_{\mathrm{o}}}{\mathrm{V}_{\mathrm{sat}}-\mathrm{v}}
$$

Deamidation reactions of $\mathrm{bz}$-Ala-Phe- $\mathrm{NH}_{2}$ and Bz-Phe-His- $\mathrm{NH}_{2}$ were followed by HPLC using the Waters liquid chomatography system (23). The following eluant system was used: A-buffer: $50 \mathrm{~mm}$-TEAP, pH 3.0, B-buffer: $50 \%$ $\mathrm{CH}_{3} \mathrm{CN}+50 \%$ A. All separations were carried out at room temperature and monitored at 254 $\mathrm{nm}$. The per cent composition could be calculated directly from the integrated peak areas since all products had the benzoyl group as a common chromophore.

\section{RESULTS}

\subsection{Specificity of malt carboxypeptidase}

The specificity of malt carboxypeptidase with respect of the $P_{1}$ position of ester substrates was investigated for the hydrolysis of a series of substrates with the general formula Bz-X-OMe (Table I). Substrates where the $\mathrm{X}$ position is occupied by an amino acid with a positively charged side chain, i.e. Lys, Arg and His, are hydrolyzed with high rates. Among the other substrates tested, high rates are only obtained with Bz-Phe-OMe whereas medium rates are observed for substrates with an aliphatic side chain with an unbranched $\beta$-carbon, i.e. Leu, Met, Ala. The substrates with a branched $\beta$-carbon, i.e. Val, Ile and $\mathrm{Thr}$ are hydrolyzed with very low rates. $\mathrm{Bz}$-Gly-OMe, Bz-Pro-OMe and Bz-Asp-OMe are not hydrolyzed at all. The concentrations of $\mathrm{Bz}$ Arg-OMe and Bz-Phe-OMe could be varied sufficiently to allow calculation of $\mathrm{k}_{\mathrm{cat}}$ and $\mathrm{K}_{\mathrm{m}}$ values from linear Lineweaver-Burk plots. The values were for Bz-Phe-OMe: $k_{\mathrm{cat}}=29000 \mathrm{~min}^{-1}, \mathrm{~K}_{\mathrm{m}}$ $=2.0 \mathrm{~mm}$ and for Bz-Arg-OMe: $\mathrm{k}_{\text {cat }}=8400 \mathrm{~min}^{-1}$, $\mathrm{k}_{\mathrm{m}}=0.39 \mathrm{mM}$.

\section{Table I.}

The specificity of malt carboxypeptidase with respect to the $\mathrm{X}$-position of $\mathrm{Bz}-\mathrm{X}$-OMe substates $(\mathrm{X}=$ amino acid residue).

\begin{tabular}{lc}
\hline Substrate & $\begin{array}{c}\mathrm{k}_{\mathrm{ca}} / \mathrm{K}_{\mathrm{m}} \\
\left(\mathrm{min}^{-1} \cdot \mathrm{mm}^{-1}\right)\end{array}$ \\
\hline Bz-Gly-OMe & 0 \\
Bz-Ala-OMe & 370 \\
Bz-Val-OMe & 22 \\
Bz-Ile-OMe & 17 \\
Bz-Leu-OMe & 420 \\
Bz-Met-OMe & 1200 \\
Bz-Phe-OMe & 14600 \\
Bz-Lys-OMe & 18300 \\
Bz-Arg-OMe & 25200 \\
Bz-His-OMe & 5600 \\
Bz-Thr-OMe & 69 \\
Bz-Pro-OMe & 0 \\
Bz-Asp-OMe & 0 \\
\hline
\end{tabular}

$\mathrm{k}_{\text {cal }} / \mathrm{K}_{\mathrm{m}}$ values were determined from full hydrolysis experiments using the following assay conditions: 0.3 mm-substrate, 0.05 M-Hepes, $1 \mathrm{~mm}$-EDTA, $2.5 \%$ methanol, $\mathrm{pH}$ 7.5. Methanol was omitted with Bz-Arg-OMe, Bz-Lys-OMe, Bz-His-OMe and Bz-Asp-OMe. 


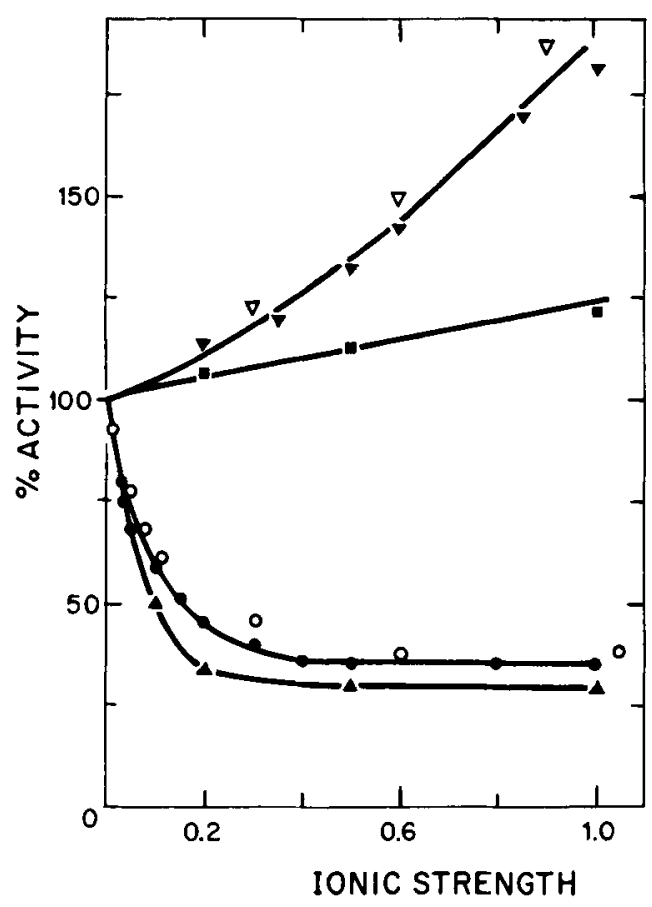

The hydrolysis of N-blocked amino acid methyl esters is influenced by addition of salts as seen in Figure 1. Both $\mathrm{NaCl}$ and $\mathrm{Na}_{2} \mathrm{SO}_{4}$ inhibit the hydrolysis of substrates where the $\mathrm{X}$ position is occupied by a positively charged amino acid residue, i.e. Arg or Lys, while activation is ob-
Figure 1. The effect of salts on the activity of malt car-

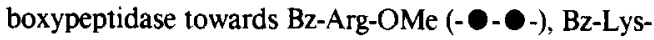

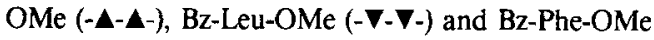
(-ש-ם-). The absissa is ionic strength, closed symbols are with $\mathrm{NaCl}$ and open symbols with $\mathrm{Na}_{2} \mathrm{SO}_{4}$. The assays were performed at $0.5 \mathrm{~mm}$-substrate in 0.05 M-Hepes, 1 mм-EDTA, pH 7.5. The assays with Bz-PheOMe and Bz-Leu-OMe contained 2.5\% (v/v) methanol. Addition of $2.5 \%(\mathrm{v} / \mathrm{v})$ methanol to assays with Bz-ArgOMe had no influence on activity neither in the absence nor in the presence of $\mathrm{NaCl}$.

served for substrates where $\mathrm{X}$ is an uncharged amino acid residue, i.e. Phe or Leu. The inhibition of Bz-Arg-OMe and Bz-Lys-OMe hydrolysis is only partial, since the activity of the enzyme reaches constant levels at high concentrations of salt. The kinetic constants for the hydrolysis of $\mathrm{Bz}$-Arg-OMe in the presence of $1 \mathrm{M}-\mathrm{NaCl}$ are: $\mathrm{k}_{\text {cat }}$ $=8000 \mathrm{~min}^{-1}$ and $\mathrm{K}_{\mathrm{m}}=2.0 \mathrm{~mm}$. In the absence of $\mathrm{NaCl}$ the values are: $\mathrm{k}_{\mathrm{cat}}=8400 \mathrm{~min}^{-1}$ and $\mathrm{K}_{\mathrm{m}}=$ $0.39 \mathrm{~mm}$. Since only $\mathrm{K}_{\mathrm{m}}$ is affected, the inhibition is competitive.

\subsection{Influence of guanidine derivatives on the specificity of malt carboxypeptidase}

An investigation of the effects of substrate analogues indicated guanidine derivatives to have a strong influence on the enzymatic proper-
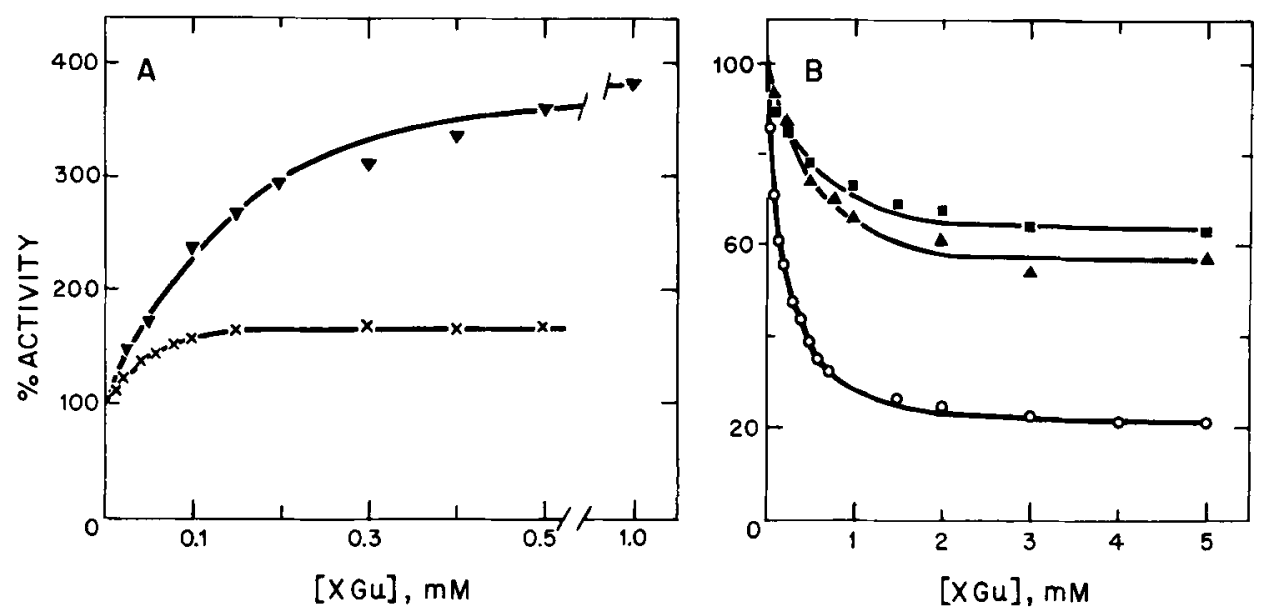

Figure 2. Effect of various guanidine derivatives on the activity of malt carboxypeptidase towards FA-Phe-OMe. The assays were performed at $0.3 \mathrm{~mm}$-substrate in $0.05 \mathrm{M}$-Hepes, $1 \mathrm{~mm}$-EDTA, pH 7.5. Panel A: Activation of malt

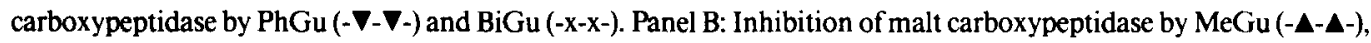
Gu (-ם-E-) and PpGu (-O-O-). 
ties of malt carboxypeptidase. As demonstrated in Figure 2A the rate of hydrolysis of FA-PheOMe is increased by $\mathrm{PhGu}$ and BiGu about 4 and 1.7 times, respectively. In contrast, Gu, MeGu and PpGu inhibit the enzyme partially (Figure 2B). The results in Figure 2 may be used for calculation of apparent dissociation constants $\left(K_{d(a p p)}\right)$ for the enzyme-effector complexes as shown in Figure 3 (see section 2.2). The values were: PhGu: $1.0 \cdot 10^{-4} \mathrm{M}$; BiGu: $3.1 \cdot 10^{-5} \mathrm{M}$; MeGu: $3.7 \cdot 10^{-4} \mathrm{M}$; Gu: $1.5 \cdot 10^{-4} \mathrm{M}$; PpGu: $1.6 \cdot 10^{-4} \mathrm{M}$.

The activation of the malt carboxypeptidase catalyzed hydrolysis of FA-Phe-OMe by $\mathrm{PhGu}$ has been studied further. Specific buffer effects are not involved since the same activation by $\mathrm{PhGu}$ is observed when $0.05 \mathrm{M}$-Tris or $1 \mathrm{M}-\mathrm{NaCl}$ is present. Neither $10 \mathrm{~mm}$-benzylamine nor 10 mm-aniline had any activating effect, suggesting that in addition to an aromatic residue the guanidine group is essential for the activation. However, $\mathrm{K}_{\mathrm{d}(\mathrm{app})}$ for $\mathrm{PhGu}$ is slightly influenced by ionic strength: In the presence of $0.3 \mathrm{M}-\mathrm{NaCl}$ and $1.0 \mathrm{M}-\mathrm{NaCl} \mathrm{K}$ d(app) is $1.4 \cdot 10^{-4} \mathrm{M}$ and $2.5 \cdot 10^{-4}$ $\mathrm{M}$, respectively, compared to $1.0 \cdot 10^{-4} \mathrm{M}$ in the absence of $\mathrm{NaCl}$. It was investigated whether $\mathrm{MeGu}$ and $\mathrm{PhGu}$ are bound to the same position on the enzyme by comparing the curve for $\mathrm{PhGu}$ activation (Figure $2 \mathrm{~A}$ ) with a similar curve obtained in the presence of $10 \mathrm{mM}-\mathrm{MeGu}$. In the event that $\mathrm{MeGu}$ and $\mathrm{PhGu}$ competed for the same position on the enzyme, high concentrations of $\mathrm{PhGu}$ would displace $\mathrm{MeGu}$, and consequently the activity of the enzyme at saturation should not be influenced by the presence of $\mathrm{MeGu}$. However, the presence of $10 \mathrm{mM}-$ $\mathrm{MeGu}$ reduces the activity of the enzyme- $\mathrm{PhGu}$ complex (at saturation with $\mathrm{PhGu}$ ) to $65 \%$, suggesting the formation of a ternary enzyme$\mathrm{PhGu}-\mathrm{MeGu}$ complex where $\mathrm{PhGu}$ and $\mathrm{MeGu}$ are bound to the enzyme at different positions. Although MeGu and PhGu apparently bind to the enzyme at different positions the binding of MeGu reduces the affinity for $\mathrm{PhGu}$ since $\mathrm{K}_{\mathrm{d}(\mathrm{app})}$ for $\mathrm{PhGu}$ increases nine fold to $8.9 \cdot 10^{-4} \mathrm{M}$.

As shown in Figure 4, $\mathrm{K}_{\mathrm{d}(\mathrm{app})}$ for the binding of PhGu to malt carboxypeptidase depends strongly on $\mathrm{pH}$ and it apparently correlates with the deprotonation of a group with a $\mathrm{pK}_{\mathrm{a}}$ below 6.5 . The degree of activation is also dependent on

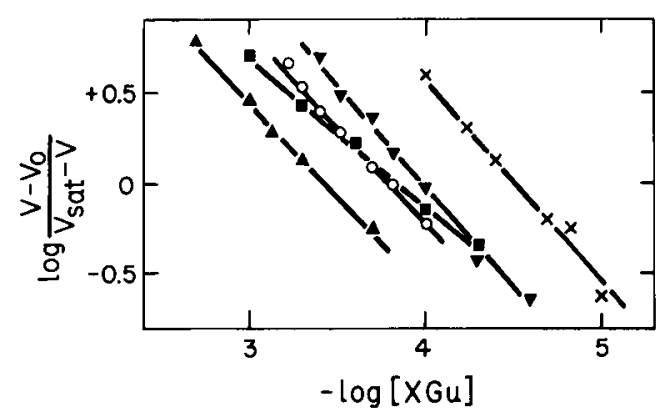

Figure 3. Determination of $\mathbf{K}_{\mathrm{d}(\mathrm{app})}$ for the compounds shown in Figure 2 using the method described in section 2.2. The symbols correspond to those used in Figure 2. The following $\mathrm{K}_{\mathrm{d}(\mathrm{app})}$ were determined: $\mathrm{PhGu}$ : $1.0 \cdot 10^{-4} \mathrm{M}$; BiGu: $3.1 \cdot 10^{-5} \mathrm{M}$; MeGu: $3.7 \cdot 10^{-4} \mathrm{M}$; Gu: $1.5 \cdot 10^{-4} \mathrm{M} ; \mathrm{PpGu}: 1.6 \cdot 10^{-4} \mathrm{M}$.

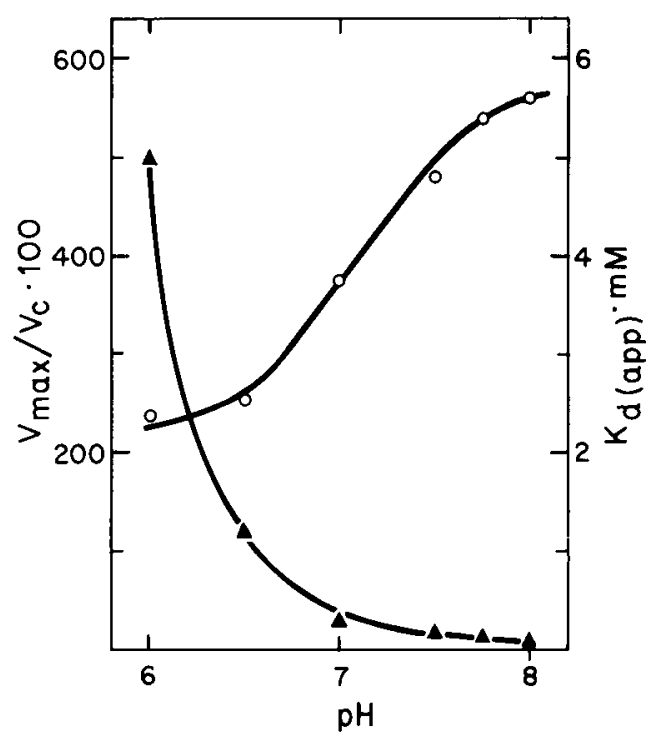

Figure 4. Influence of $\mathrm{pH}$ on $\mathrm{K}_{\mathrm{d}(\mathrm{app})}$ of the enzyme-

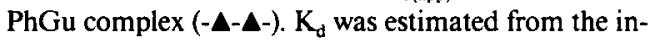
fluence of the concentration of phenylguanidine on the activity of malt carboxypeptidase towards FA-PheOMe according to the procedure described in section 2.2. Assay conditions: $0.05 \mathrm{M}$-Hepes or $0.05 \mathrm{M}-\mathrm{Mes}, 1$ mм-EDTA, 0.3 mм-FA-Phe-OMe, 2.5\% methanol, $4.7 \cdot 10^{-9} \mathrm{M}$ enzyme. The percentage activation $\left(\mathrm{V}_{\max } /\right.$ $\mathrm{V}_{\mathrm{c}}$ ) at each $\mathrm{pH}$ value is also indicated (-O-O-). $\mathrm{V}_{\max }$ is the rate of hydrolysis at saturating concentrations of PhGu: $5 \mathrm{~mm}$ at $\mathrm{pH} 7$ to 8 and $50 \mathrm{~mm}$ at $\mathrm{pH} 6$ and 6.5 . $\mathrm{V}_{\mathrm{c}}$ is the rate of hydrolysis in the absence of $\mathrm{PhGu}$ at the indicated $\mathrm{pH}$ value. 
Table II.

Influence of MeGu, PhGu and BiGu on the malt carboxypeptidase catalyzed hydrolysis of different ester substrates.

\begin{tabular}{lccc}
\hline & \multicolumn{3}{c}{$\left(\mathrm{v} / \mathrm{v}_{0}\right) \times 100$ in the presence of } \\
\cline { 2 - 4 } Substrate & MeGu & PhGu & BiGu \\
\hline Bz-Ala-OMe & 55 & 570 & 280 \\
Bz-Leu-OMe & 45 & 900 & 290 \\
Bz-Phe-OMe & 45 & 310 & 170 \\
FA-Phe-OMe & 55 & 380 & 170 \\
Bz-Arg-OMe & 50 & 340 & 220 \\
Ac-Arg-OMe & & 280 & \\
Bz-Phe-OEt & 55 & 50 & 35 \\
Bz-Arg-OEt & 50 & 80 & 60 \\
\hline
\end{tabular}

The assays were performed at a substrate concentration of $0.5 \mathrm{~mm}$ in $0.05 \mathrm{~m}$-Hepes, $1 \mathrm{~mm}$-EDTA, pH 7.5. All assays except those with Ac-Arg-OMe, Bz-Arg-OMe and $\mathrm{Bz}-\mathrm{Arg}-\mathrm{OEt}$ contained $2.5 \%(\mathrm{v} / \mathrm{v})$ methanol. The following concentrations of effector was used: $10 \mathrm{~mm}$ $\mathrm{MeGu}, 0.75 \mathrm{~mm}-\mathrm{PhGu}$ and $0.1 \mathrm{~mm}-\mathrm{BiGu}$.

$\mathrm{pH}$, with the highest activation about $\mathrm{pH} 8$. At pH 5.0 where saturation of the enzyme with PhGu cannot be obtained due to the limited solubility of $\mathrm{PhGu}$, the enzyme-PhGu complex is still more active than the enzyme alone: at $\mathbf{5 0}$ $\mathrm{mm}-\mathrm{PhGu} \mathrm{v} / \mathrm{v}_{0}$ is 1.8 .
Table II summarizes the effects of $\mathrm{MeGu}$, $\mathrm{PhGu}$ and BiGu on the activity of malt carboxypeptidase towards different ester substrates. MeGu inhibits all of the substrates regardless of the amino acid residue in the $P_{1}$ position and the alcohol residue in the $P_{1}^{\prime}$ position of the substrate. In contrast, $\mathrm{PhGu}$ and $\mathrm{BiGu}$ increase the rate of hydrolysis of the $\mathrm{N}$-blocked methyl esters while the rates of hydrolysis of the ethyl esters $\mathrm{Bz}-\mathrm{Arg}-\mathrm{OEt}$ and $\mathrm{Bz}-\mathrm{Phe}-\mathrm{OEt}$ are reduced, thus demonstrating a specific influence of the leaving group of the substrate.

The effects of MeGu and PhGu on the enzymatic properties of malt carboxypeptidase were further investigated by determination of the kinetic constants for a series of ester substrates Bz-Arg-OX with varying leaving group ( $X=M e$, $\mathrm{Et}, \mathrm{Pr}, \mathrm{Bu}$ ) (Table III). With all of these substrates MeGu decrease $\mathrm{k}_{\text {cat }}$ and increase $\mathrm{K}_{\mathrm{m}}$, and there is no apparent correlation with the size of the alcohol leaving group of the substrate. The effects of $\mathrm{PhGu}$ on the kinetic parameters for the hydrolysis of this series of substrates is more interesting. With all of the substrates an increase in $\mathrm{k}_{\text {cal }}$ is seen, the highest with Bz-Arg-OMe which increases approximately 3 fold. In contrast to this, $\mathrm{K}_{\mathrm{m}}$ varies in both directions: it decreases from $0.39 \mathrm{~mm}$ to $0.16 \mathrm{~mm}$ with Bz-Arg-OMe and increases approximately 4 fold with Bz-Arg-OEt,

Table III.

The influence of MeGu and PhGu on malt carboxypeptidase catalyzed hydrolysis of ester substrates with different alcohol leaving group.

\begin{tabular}{llrrrr}
\hline & & \multicolumn{4}{c}{ Substrate } \\
\cline { 3 - 6 } & & Bz-Arg-OMe & Bz-Arg-OEt & Bz-Arg-OPr & Bz-Arg-OBu \\
\hline \multirow{3}{*}{ No effector } & $\mathrm{k}_{\mathrm{cat}}$ & 8400 & 11400 & 11000 & 11600 \\
added & $\mathrm{K}_{\mathrm{m}}$ & 0.39 & 0.11 & 0.034 & 0.022 \\
\hline \multirow{3}{*}{$+\mathrm{MeGu}$} & $\mathrm{k}_{\mathrm{ca}} / \mathrm{K}_{\mathrm{m}}$ & 21500 & 104000 & 324000 & 527000 \\
& $\mathrm{k}_{\mathrm{cat}}$ & 6300 & 6700 & 6300 & 6000 \\
& $\mathrm{~K}_{\mathrm{m}}$ & 1.15 & 0.17 & 0.065 & 0.042 \\
& $\mathrm{k}_{\mathrm{ca}} / \mathrm{K}_{\mathrm{m}}$ & 5500 & 39000 & 97000 & 140000 \\
\hline \multirow{3}{*}{+ PhGu } & $\mathrm{k}_{\mathrm{cat}}$ & 23600 & 20000 & 16400 & 19900 \\
& $\mathrm{~K}_{\mathrm{m}}$ & 0.16 & 0.43 & 0.12 & 0.095 \\
& $\mathrm{k}_{\mathrm{ca}} / \mathrm{K}_{\mathrm{m}}$ & 150000 & 47000 & 140000 & 210000 \\
\hline
\end{tabular}

The rate of hydrolysis was determined spectrophotometrically in $0.05 \mathrm{M}$-Hepes, $1 \mathrm{~mm}$-EDTA, pH 7.5, using substrate concentrations of $0.03-1.3 \mathrm{~mm} \mathrm{k}_{\text {cat }}$ values are in min $^{-1}$ and $\mathrm{K}_{\mathrm{m}}$ values in $\mathrm{mm}$. MeGu and PhGu were used at saturating concentrations, $5 \mathrm{~mm}$ and $0.75 \mathrm{~mm}$, respectively. 


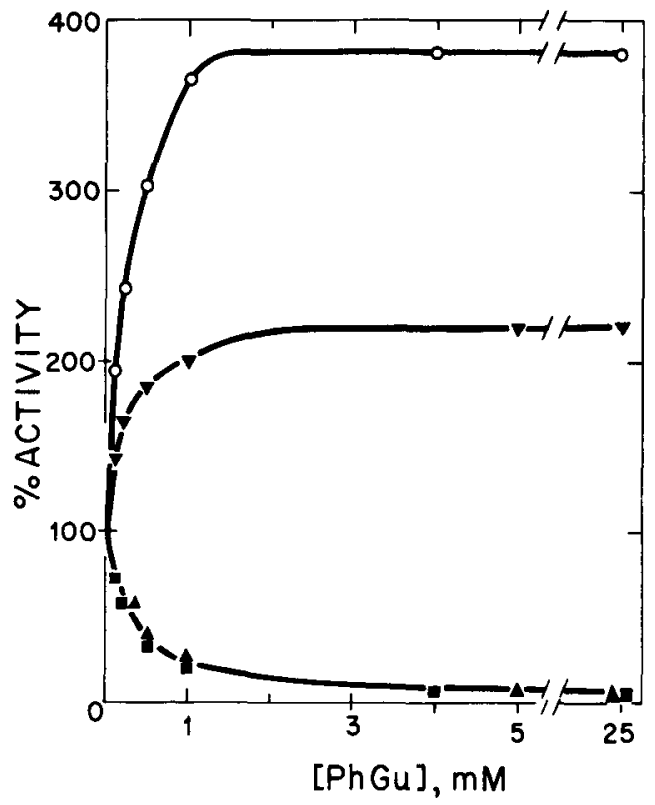

Figure 5. Effect of PhGu on the activities of malt carboxypeptidase. All assays were performed in 0.05 M-Hepes, 1 mm-EDTA, 2.5\% methanol, pH 7.5 at a substrate concentration of $0.3 \mathrm{~mm}$. The indicated concentrations of phenylguanidine were included in the assays. FA-Phe-OMe, -O-O-; FA-Phe-Ala-OH, - - - -; FA-Phe-Gly-NH ${ }_{2},-\Delta-\Delta-;$ FA-Phe- $\mathrm{NH}_{2},-\mathbf{\nabla}-\mathbf{\nabla}$.

$-\mathrm{OPr}$ and $-\mathrm{OBu}$. These results indicate that $\mathrm{PhGu}$ interacts with the $S_{1}$ position of the enzyme to which the leaving group of ester substrates is bound and it does this in a manner which renders methyl esters better substrates of the enzyme and ethyl, propyl and butyl esters worse substrates. HPLC analysis of the reaction mixtures has confirmed that in the presence of $\mathrm{PhGu}$ $\mathrm{Bz}-\mathrm{Arg}-\mathrm{OH}$ is the only product formed from $\mathrm{Bz}$ Arg-OMe suggesting that $\mathrm{PhGu}$ does not function as a nucleophile in the reaction.

Since PhGu interacts with the binding of the leaving group of ester substrates to malt carboxypeptidase, it was investigated whether it interacted similarly with the leaving group of peptide and peptide amide substrates. The substrates: FA-Phe $-\mathrm{OMe}$, FA-Phe $=\mathrm{Ala}-\mathrm{OH}$, FA-Phe $-\mathrm{NH}_{2}$ and FA-Phe ${ }^{ \pm}$Gly- $\mathrm{NH}_{2}$ were used to measure the esterase, peptidase, amidase and peptidyl amino acid amide hydrolase activities, respectively. As seen from Figure 5, binding of $\mathrm{PhGu}$ to the en zyme reduces its activity towards FA-Phe $-\mathrm{Ala}-\mathrm{OH}$

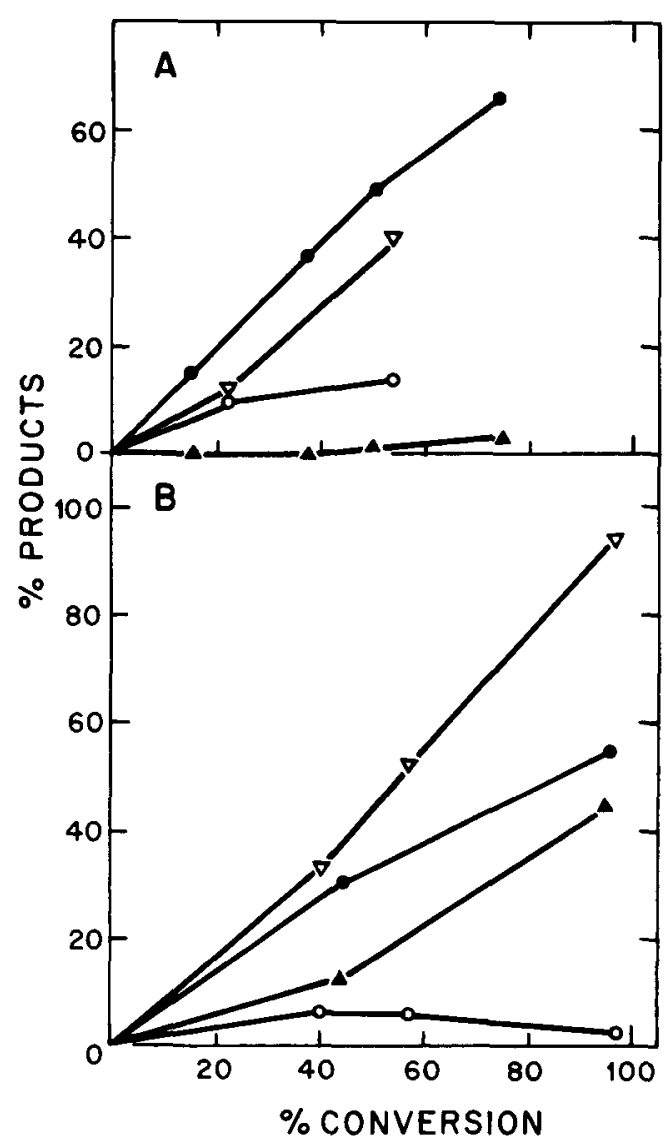

Figure 6. The influence of $\mathrm{PhGu}$ on malt carboxypeptidase catalyzed deamidation reactions. The figures list the appearence of $\mathrm{Bz}-\mathrm{X}-\mathrm{OH}$ and $\mathrm{Bz}-\mathrm{X}-\mathrm{Y}-\mathrm{OH}$ versus the degree of conversion of substrate (Bz-X-Y-NH$\left.{ }_{2}\right)$. Panel $\mathrm{A}$ : Deamidation of Bz-Ala-Phe- $\mathrm{NH}_{2}$. Triangles $=\mathrm{Bz}$ Ala-OH, circles = Bz-Ala-Phe-OH; closed symbols: reaction performed in the presence of $10 \mathrm{~mm}-\mathrm{PhGu}$, open symbols: reaction performed in the absence of $\mathrm{PhGu}$. Reaction conditions: $2.5 \mathrm{~mm}$-Bz-Ala-Phe- $\mathrm{NH}_{2}, 10 \%$ (v/v) DMF, 1 mM-EDTA, 5.0 $\mu$ M-enzyme, pH 7.5. The last point is at 60 minutes. Panel $\mathrm{B}$ : Deamidation of $\mathrm{Bz}$ Phe-His- $\mathrm{NH}_{2}$. Triangles $=\mathrm{Bz}-\mathrm{Phe}-\mathrm{OH}$, circles $=\mathrm{Bz}-$ Phe-His-OH; closed symbols: reaction performed in the presence of $10 \mathrm{mM}-\mathrm{PhGu}$, open symbols: reaction performed in the absence of $\mathrm{PhGu}$. Reaction conditions: 2.5 mM-Bz-Phe-His- $\mathrm{NH}_{2}, 10 \%(\mathrm{v} / \mathrm{v})$ DMF, $1 \mathrm{~mm}-$ EDTA, $5.0 \mu \mathrm{M}$-enzyme, $\mathrm{pH}$ 7.5. The last point is at 40 minutes. 
and FA-Phe $\unrhd$ Gly- $\mathrm{NH}_{2}$ to less than $3 \%$ of the control. Contrary to this, the rate of hydrolysis of FA-Phe $=\mathrm{OMe}$ and FA-Phe $-\mathrm{NH}_{2}$ is increased to $380 \%$ and $220 \%$ of the control, respectively. These results indicate that the hydrolysis of substrates with large groups in the $\mathrm{P}_{1}$ position, i.e. -Ala-OH and - Gly- $\mathrm{NH}_{2}$, is inhibited while the hydrolysis of those with small groups in this position is activated, i.e., -OMe and $-\mathrm{NH}_{2}$.

The effect of $\mathrm{PhGu}$ on the various activities of malt carboxypeptidase is reflected similarly in the deamidation of peptide amides. Reaction of Bz-Ala-Phe- $\mathrm{NH}_{2}$ with malt carboxypeptidase forms two products: $\mathrm{Bz}-\mathrm{Ala}-\mathrm{Phe}-\mathrm{OH}$ by release of $\mathrm{NH}_{3}$ (amidase activity) and Bz-Ala-OH. The latter arise either by direct release of $\mathrm{H}-\mathrm{Phe}-\mathrm{NH}_{2}$ (peptidyl amino acid amide hydrolase activity) or by secondary release of $\mathrm{H}-\mathrm{Phe}-\mathrm{OH}$ from $\mathrm{Bz}-$ Ala-Phe-OH (peptidase activity). The results in Figure 6A demonstrate that binding of $\mathrm{PhGu}$ to the enzyme exerts a pronouced effect on the yield of the deamidation product Bz-Ala-Phe-OH. In the absence of $\mathrm{PhGu}$, the yield was less than $45 \%$ while in the presence of $\mathrm{PhGu}$, the yield was 95 $100 \%$. Figure $6 \mathrm{~B}$ demonstrates a similar effect of $\mathrm{PhGu}$ on the deamidation of $\mathrm{Bz}-\mathrm{Phe}-\mathrm{His}-\mathrm{NH}_{2}$, where the yield of deamidation product $\mathrm{Bz}-\mathrm{Phe}$ His-OH is increased from $3-15 \%$ in the absence of $\mathrm{PhGu}$ to $55-70 \%$ in the presence of $\mathrm{PhGu}$. Thus, the reactions competing with the deamidation reaction are clearly suppressed in both cases.

\section{DISCUSSION}

The X-ray structures of two enzymes which employ similar catalytic mechanisms, the metallo enzymes thermolysin and carboxypeptidase A, have indicated the explanation for the inability of a carboxypeptidase to cleave any other peptide bonds than the C-terminal as opposed to a protease which cleaves peptide bonds in the interior of polypeptide chains. Thermolysin possesses multiple binding sites for the leaving, group, $S_{1}, S_{2} \ldots S_{n}$, located in an extended cleft of the enzyme while carboxypeptidase $A$ possesses only a single binding site for the leaving group i.e. $\mathrm{S}_{1}$, which is located in a dead-end pocket in the enzyme $(14,16,17)$. The active sites of the serine proteases are similarly located in clefts $(15,18)$, and in analogy with carboxypeptidase $A$ we might expect dead-end structures in the serine carboxypeptidases. In spite of such conceivable differences between serine proteases and serine carboxypeptidases they share the capability to release alcohols from peptide esters and ammonia and/or the C-terminal amino acid amide from peptide amides (5) because both groups of enzymes possess the required binding sites for these activities: $S_{1}$ in the $C$-terminal direction, and $S_{1}, S_{2}, \ldots, S_{n}$ in the $N$-terminal direction of the scissile bond. Thus, it is reasonable to compare the side chain specificity of malt carboxypeptidase catalyzed ester hydrolysis with the specificities of proteases as well as other serine carboxypeptidases.

The malt carboxypeptidase catalyzed hydrolysis of ester substrates with the general formula Bz-X-OMe indicate a wide specificity with preference for substrates where $X=P h e, A r g$, Lys over those where the X-position is occupied by an amino acid residue with a neutral or acidic aliphatic side chain. The high $\mathrm{k}_{\mathrm{cat}} / \mathrm{K}_{\mathrm{m}}$ value for the hydrolysis of Bz-Phe-OMe is mainly due to a high $\mathrm{k}_{\mathrm{cat}}$ value while for Bz-Arg-OMe it is mainly due to a low $\mathrm{K}_{\mathrm{m}}$ value. The competitive inhibition by $\mathrm{NaCl}$ of malt carboxypeptidase catalyzed hydrolysis of $\mathrm{Bz}$-Arg-OMe indicates the presence of a negatively charged residue on the enzyme which participates in the binding of substrates with positively charged side chains in the $P_{1}$ position. Apparently this residue does not influence the binding of substrates with a neutral side chain in the $P_{1}$ position. The subtilisins have a similar wide specificity and it has been suggested that this is due to different modes of productive binding for substrates with an aromatic and a basic residue in the $P_{1}$ position (8). A similar situation could explain the wide specificity of malt carboxypeptidase. The specifity of malt carboxypeptidase catalyzed hydrolysis of ester substrates has some resemblance with Penicillocarboxypeptidase $S-2(10)$, but it is very different from that of carboxypeptidase $Y$ from yeast, which with respect to the $P_{1}$ position of ester substrates has a specificity similar to that of chymotrypsin, i.e. it hydrolyses Bz-Phe-OMe very fast but almost completely lack the capability to hydrolyse Bz-Arg-OMe and Bz-LysOMe (4).

The acylation step appears to be rate-limiting in the malt carboxypeptidase catalyzed hydro- 
lysis of the ester substrate Z-Lys-ONp (to be published). Provided this also applies to the ester substrates Bz-Arg-OX ( $\mathrm{X}=\mathrm{Me}, \mathrm{Et}, \mathrm{Pr}, \mathrm{Bu}), \mathrm{K}_{\mathrm{m}}$ will be approximately equal to $\mathrm{K}_{\mathrm{s}}$ and the decreasing $\mathrm{K}_{\mathrm{m}}$ values in the sequence -OMe, -OEt, -OPr, -OBu then suggest that the interaction between enzyme and alcohol leaving group is mainly due to hydrophobic interactions. This may explain why MeGu apparently does not interact with the $S_{1}$ position whereas the more hydrophobic $\mathrm{PhGu}$ interacts in a manner which results in a decrease in $\mathrm{K}_{\mathrm{m}}$ for $\mathrm{Bz}$-Arg-OMe and an increase in $\mathrm{K}_{\mathrm{m}}$ for $\mathrm{Bz}-\mathrm{Arg}-\mathrm{OEt}(-\mathrm{OPr},-\mathrm{OBu})$. Thus, binding of $\mathrm{PhGu}$ presumably changes the properties of the $S_{1}$ site such that the binding of $\mathrm{Bz}$-Arg-OMe becomes tighter. The increased $\mathrm{k}_{\text {cat }}$ for all the substrates Bz-Arg-OX is then attributed to an increased rate of the rate-limiting step, i.e. acylation.

The different effects of $\mathrm{PhGu}$ on the activities of malt carboxypeptidase towards FA-Phe $=O M e$, FA-Phe $-\mathrm{NH}_{2}$, FA-Phe $\_$Ala-OH and FA-Phe ${ }^{\prime}$ Gly$\mathrm{NH}_{2}$ indicate that when the leaving group of the substrate is large, i.e. -Ala-OH and -Gly- $\mathrm{NH}_{2}$, it competes with $\mathrm{PhGu}$ for the same site. However, when the leaving group of the substrate is small, i.e. $-\mathrm{NH}_{2}$ and $-\mathrm{OMe}, \mathrm{PhGu}$ exerts an activating effect, indicating that the $S_{1}$ binding site may accomodate $\mathrm{PhGu}$ and the small leaving group simultaneously.

At present, no enzyme has been described which catalyzes the specific release of $\mathrm{NH}_{3}$ from the C-terminal of peptide amides. Although serine and sulfhydryl proteases exhibit amidase activity, they cleave in addition internal peptide bonds and are thus of limited use in deamidation reactions. The serine carboxypeptidases have similar limitations, since these enzymes release both ammonia and the C-terminal amino acid amide (2). The present observation that $\mathrm{PhGu}$ increases the amidase activity of malt carboxypeptidase while it decreases the peptidase and peptidyl amino acid amide hydrolase activities is of interest since the yields of deamidation reactions may be increased as demonstrated with $\mathrm{Bz}$ Phe-His- $\mathrm{NH}_{2}$ and Bz-Ala-Phe-NH . Such deamidation reactions are essential in stepwise enzymatic peptide synthesis, where they function as deblocking reactions $(2,6,23)$.

\section{ACKNOWLEDGEMENTS}

The authors acknowledge Ms. IRENE SIMONSEN and Mr. ThORKILD BEENFELDT for excellent technical assistance.

\section{REFERENCES}

1. Blumberg, S. \& B.L. Vallee: Superactivation of thermolysin by acylation with amino acid N-hydroxysuccinimide esters. Biochemistry 14 , 2410-2419 (1975)

2. BREDDAM, K., F. WIDMER \& J.T. JohanSEN: Carboxypeptidase $\mathrm{Y}$ catalyzed transpeptidations and enzymatic peptide synthesis. Carlsberg Res. Commun. 45, 237-247 (1980)

3. Breddam, K., F. Widmer \& J.T. Johansen: Influence of the substrate structure on carboxypeptidase $Y$ catalyzed peptide bond formation. Carlsberg Res. Commun. 45, 361-367 (1980)

4. BREDDAM, K.: Modification of the single sulfhydryl group of carboxypeptidase $Y$ with mercurials. Influence on enzyme specificity. Carlsberg Res. Commun. 48, 9-19(1983)

5. Breddam, K., S. Sørensen \& M. Ottesen: Isolation of a carboxypeptidase from malted barley by affinity chromatography. Carlsberg Res. Commun. 48, 217-230 (1983)

6. Breddam, K., F. Widmer \& J.T. Johansen: Amino acid methyl esters as amine components in CPD-Y catalyzed peptide synthesis: Control of side reactions. Carlsberg Res. Commun. 48 , 231-237 (1983)

7. Breddam, K. \& J.T. Johansen: Semisynthesis of human insulin using chemically modified carboxypeptidase Y. Carlsberg Res. Commun. (submitted for publication)

8. Glazer, A.N.: Esteratic reactions catalyzed by subtilisins. J. Biol. Chem. 242, 433-436 (1967)

9. HAYASHI, R.: Carboxypeptidase Y. In Methods Enzymol., L. Lorand, ed., Academic Press, vol 45, 568-587 (1976)

10. Hofman, T: Penicillocarboxypeptidases S-l and S-2. In Methods Enzymol., L. Lorand, ed., Academic Press, vol 45, 587.599 (1976)

11. Inagami, T. \& T. Murachi: The mechanism of the specificity of trypsin catalysis. J. Biol. Chem. 239, 1395-1401 (1964)

12. JaCobsen, C.F., J. Leonis, K. LinderstromLANG \& M. OTTESEN: The pH-stat and its use in biochemistry. Meth. Biochem. Anal. vol 4, 171210 (1957)

13. Johansen, J.T., K. Breddam \& M. Ottesen: Isolation of carboxypeptidase $Y$ by affinity chromatography. Carlsberg Res. Commun. 41, 1-14 (1976) 
14. KeSTER, W.R. \& B.W. MATThews: Comparison of the structures of carboxypeptidase $A$ and thermolysin. J. Biol. Chem. 252, 7704-7710 (1977)

15. KRAUT, J., J.D. Robertus, J.S. Birktoft \& R.A. ALDEN: The aromatic substrate binding site in subtilisin BPN' and its resemblance to chymotrypsin. Cold Spring Harbor Symp. Quant. Biol. 36, 117-123 (1971)

16. Quiocho, F.A. \& W.N. LIPSCOMB: Carboxypeptidase A: A protein and an enzyme. Academic Press, N.Y., Eds. C.B. Anfinsen, J.T. Edsall \& F.M. Richards. Adv. Prot. Chem. 25, 1-53 (1971)

17. RIORDAN, J.F: Functional arginyl residues in carboxypeptidase A. Modification with butanedione. Biochemistry 12, 3915-3923 (1973)

18. Robertus, J.D., R.A. Alden, J.J. BiRkToft, J. Kraut, J.C.Powers \& P.E. Wilcox: An X-ray crystallographic study of the binding of peptide chloromethyl ketone inhibitors to subtilisin BPN'. Biochemistry 11, 2439-2449 (1972)
19. SEGEL, I.: Biochemical calculations. John Wiley \& Sons, New York, pp. 393-395 (1968)

20. SvendSen, I.: Chemical modifications of the subtilisins with special reference to the binding of large substrates. A review. Carlsberg Res. Commun. 41, 237-291 (1977)

21. WidMer, F. \& J.T. Johansen: Enzymatic peptide synthesis. Carboxypeptidase Y catalyzed formation of peptide bonds. Carlsberg Res. Commun. 44, 37-46 (1979)

22. WidMer, F., K. BredDam \& J.T. JohanSEn: Carboxypeptidase $\mathrm{Y}$ catalyzed peptide synthesis using amino acid alkyl esters as amine components. Carlsberg Res. Commun. 45, 453-463 (1980)

23. WidMER, F., K. BREDdAM \& J.T. JohANSEN: Influence of the structure of amine components in carboxypeptidase $\mathrm{Y}$ catalyzed amide bond formation. Carlsberg Res. Commun. 46, 97-106 (1981) 